\title{
Atom efficiency and catalysis in organic synthesis*
}

\author{
Roger A. Sheldon \\ Delft University of Technology, Organic Chemistry and Catalysis, Julianalaan 136, \\ 2628 BL Delft, The Netherlands
}

\begin{abstract}
The key to waste minimization in fine chemicals manufacture is the widespread substitution of classical organic syntheses employing stoichiometric amounts of inorganic reagents with cleaner, catalytic alternatives. The $\mathrm{E}$ factors (by waste per $\mathrm{kg}$ product) of chemical processes increase dramatically on going downstream from bulk to fine chemicals and pharmaceuticals, mainly owing to the use of "stoichiometric" methods. The concept of atom efficiency is a useful tool for rapid evaluation of the amount of waste generated by alternative processes. The general theme of atom-efficient, catalytic processes is illustrated with industrially relevant examples. These include catalysis by solid acids and bases, catalytic reductions and oxidations, catalytic $\mathrm{C}-\mathrm{C}$ bond formation, asymmetric catalysis, biocatalysis, and catalysis in novel media (aqueous and fluorous biphasic systems, supercritical fluids, and ionic liquids).
\end{abstract}

\section{INTRODUCTION}

Increasingly, stringent environmental legislation has generated a pressing need for cleaner methods of chemical production, for instance, technologies that reduce or, preferably, eliminate the generation of waste and avoid the use of toxic and/or hazardous reagents and solvents [1-4]. This trend toward green chemistry [5-7] necessitates a paradigm shift from the traditional concept of process efficiency, that focuses exclusively on chemical yield, to one that assigns economic value to eliminating waste.

\section{E FACTORS AND ATOM EFFICIENCY}

The magnitude of the waste problem is readily apparent from a consideration of the waste generated per $\mathrm{kg}$ of product, designated as the $\mathrm{E}$ factor, in various segments of the chemical industry (Table 1).

Waste is defined as everything produced in the process except the desired product. It consists primarily of inorganic salts (e.g., sodium chloride, sodium sulfate, ammonium sulfate), formed in the reaction or subsequent neutralization steps, or derived from stoichiometric inorganic reagents (e.g., a stoichiometric metal oxidant). The $\mathrm{E}$ factor increases dramatically on going downstream from bulk to fine chemicals and specialties such as pharmaceuticals. This is partly owing to the fact that the production of fine chemicals involves multi-step syntheses but is also a reflection of the use of stoichiometric reagents rather than catalytic methodologies.

The atom utilization [8], atom efficiency, or atom economy concept [9] is an extremely useful tool for rapid evaluation of the amount of waste generated by alternative routes to a specific product [10]. It is calculated by dividing the molecular weight of the desired product by the sum total of the molecular weights of all substances produced in the stoichiometric equation for the reaction(s) involved. The comparison is made on a theoretical basis (i.e., 100\% chemical yield). The theoretical $\mathrm{E}$ factor is readily derived from the atom efficiency, for example, an atom efficiency of $40 \%$ corresponds to an $\mathrm{E}$ factor of 1.5. In practice, the $\mathrm{E}$ factor is much higher as the yield is not $100 \%$, and an excess of

*Pure Appl. Chem. Vol. 72, No. 7, 2000. A special topic issue on green chemistry. 
Table 1 The E factor.

\begin{tabular}{lcc}
\hline Industry segment & Product tonnage & $\mathrm{kg}$ waste/kg product \\
\hline Oil refining & $10^{6}-10^{8}$ & $<0.1$ \\
Bulk chemicals & $10^{4}-10^{6}$ & $<1-5$ \\
Fine chemicals & $10^{2}-10^{4}$ & $5 \rightarrow>50$ \\
Pharmaceuticals & $10-10^{3}$ & $25->100$ \\
\hline
\end{tabular}

reagent(s) is often used, and solvent losses and salt generation in subsequent neutralization steps have to be taken into account. A further refinement would also take the energy consumption of alternative routes into account as this also generates waste $\left(\right.$ mostly as $\left.\mathrm{CO}_{2}\right)$. Furthermore, in order to evaluate the environmental impact of alternative routes we must also take the nature of the waste into account. To this end we introduced [1] the term environmental quotient (EQ), which is E multiplied by an arbitrarily assigned unfriendliness quotient, $\mathrm{Q}$. For example, $\mathrm{NaCl}$ could be assigned a $\mathrm{Q}$ value of 1 and heavy metal salts, say 100-1000, depending on their toxicity, ease of recycling, etc. Although the magnitude of $\mathrm{Q}$ is obviously debatable it is possible to quantitatively assess the environmental impact of processes on this basis.

\section{THE ROLE OF CATALYSIS}

As noted above, a primary cause of waste generation is the use of stoichiometric inorganic reagents. Fine chemicals manufacture is rampant with antiquated classical "stoichiometric" technologies, for example, stoichiometric reductions with metals ( $\mathrm{Na}, \mathrm{Mg}, \mathrm{Fe}, \mathrm{Zn})$ and metal hydrides $\left(\mathrm{LiAlH}_{4}, \mathrm{NaBH}_{4}\right)$ and oxidations with permanganate or chromium(VI) reagents. The solution is simple: replacement of stoichiometric methodologies with cleaner, catalytic alternatives. For example, the atom efficiencies of the stoichiometric oxidation of a secondary alcohol, to the corresponding ketone, with chromium trioxide in sulfuric acid and catalytic oxidation with $\mathrm{O}_{2}$ are compared in Fig. 1.

\section{CATALYSIS WITH SOLID ACIDS AND BASES}

Another major cause of waste is the widespread use of mineral $\left(\mathrm{H}_{2} \mathrm{SO}_{4}, \mathrm{H}_{3} \mathrm{PO}_{4}\right.$, etc. $)$ and Lewis acids $\left(\mathrm{AlCl}_{3}, \mathrm{ZnCl}_{2}\right.$, etc.), often in stoichiometric amounts, which cannot be easily recovered and recycled.

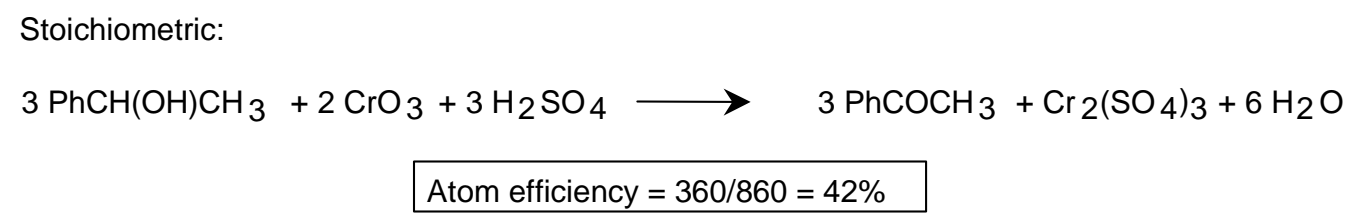

Catalytic:

$\mathrm{PhCH}(\mathrm{OH}) \mathrm{CH}_{3}+1 / 2 \mathrm{O}_{2} \stackrel{\text { catalyst }}{\stackrel{\text { PHCm efficiency }}{\longrightarrow}=120 / 138=87 \%} \mathrm{PHCOCH}_{3}+\mathrm{H}_{2} \mathrm{O}$
Atom

Fig. 1 Atom efficiency of stoichiometric vs catalytic oxidation. 


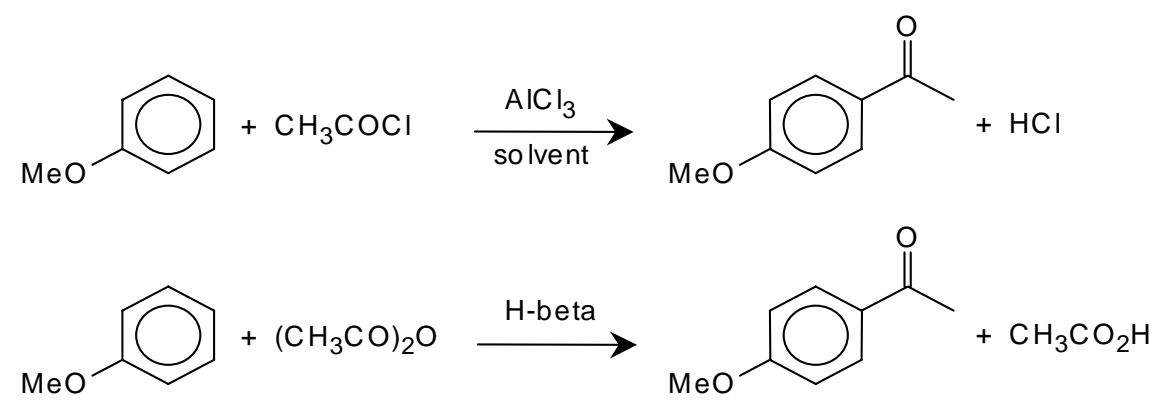

\section{Homogeneous}

$\mathrm{AlCl}_{3}>1$ equivalent

Solvent

Hydrolysis of products

Phase separation

Distillation organic phase

Solvent recycle

$85-95 \%$ yield

$4.5 \mathrm{~kg}$ aqueous effluent per $\mathrm{kg}$

\author{
Heterogeneous \\ $\mathrm{H}$-beta, catalytic \& regenerable \\ No solvent \\ No water necessary \\ Distillation organic phase \\ $-$ \\ $>95 \%$ yield/higher purity \\ $0.035 \mathrm{~kg}$ aqueous effluent per $\mathrm{kg}$
}

Fig. 2 Friedel-Crafts acylation: classical vs zeolite-catalyzed.

Hence, there is a marked trend towards their replacement by recyclable solid acids such as zeolites, acidic clays, and heteropoly acids [11].

A pertinent example is Friedel-Crafts acylation, which is a widely used reaction in fine chemicals manufacture. In contrast to Friedel-Crafts alkylations, acylations require more than one equivalent of, for example, $\mathrm{AlCl}_{3}$ or $\mathrm{BF}_{3}$ owing to strong complexation of the Lewis acid by the ketone product. Although zeolites have already widely replaced mineral and Lewis acids in Friedel-Crafts alkylations, the more difficult acylations have proven recalcitrant. Nevertheless, Rhône Poulenc has recently reported [12] the first commercial application of a zeolite-catalyzed aromatic acylation: the liquid-phase acetylation of anisole over zeolite beta (Fig. 2).

The zeolite-catalyzed acylation employs acetic anhydride as the acylating agent and requires no solvent. In contrast, the classical process uses acetyl chloride in combination with $>1$ equiv. of $\mathrm{AlCl}_{3}$ (the use of anhydride would require $>2$ equivs. of $\mathrm{AlCl}_{3}$ ) and a chlorinated hydrocarbon as solvent. The new process avoids the generation of $\mathrm{HCl}$ in both the acylation and the synthesis of the acetyl chloride. The original process generated $4.5 \mathrm{~kg}$ of aqueous effluent (containing $\mathrm{AlCl}_{3}, \mathrm{HCl}$, chlorinated hydrocarbon residues, and acetic acid) per $\mathrm{kg}$ of p-methoxy acetophenone. The catalytic alternative generates $0.035 \mathrm{~kg}$ of aqueous effluent (i.e., $>100$ times less), consisting of $99 \% \mathrm{H}_{2} \mathrm{O}, 0.8 \% \mathrm{CH}_{3} \mathrm{CO}_{2} \mathrm{H}$, and $<0.2 \%$ other organics, per kg of product. Work-up consists of catalyst filtration and distillation of the product. Moreover, a higher chemical yield (>95\% vs $85-95 \%$ ) is achieved, the catalyst is recyclable, and the number of unit operations is reduced from twelve to two.

The above process involves the acylation of a relatively reactive aromatic substrate. For broad application in fine chemicals manufacture the methodology should also be applicable to less reactive substrates. However, attempts to effect the zeolite-catalyzed acylation of less-reactive aromatic compounds were generally unsuccessful, and we attributed this to an adsorption imbalance, for example, the more polar acylating agent is selectively adsorbed, preventing access of the aromatic substrate to the active site [11]. This problem can be largely circumvented by performing the reaction in the vapor phase and the successful acetylation of benzene with acetic acid over $\mathrm{H}-\mathrm{ZSM}-5(\mathrm{Si} / \mathrm{Al}=41)$, at $250{ }^{\circ} \mathrm{C}$ and 1 bar in a tubular reactor, has been reported [13].

(C) 2000 IUPAC, Pure and Applied Chemistry 72, 1233-1246 


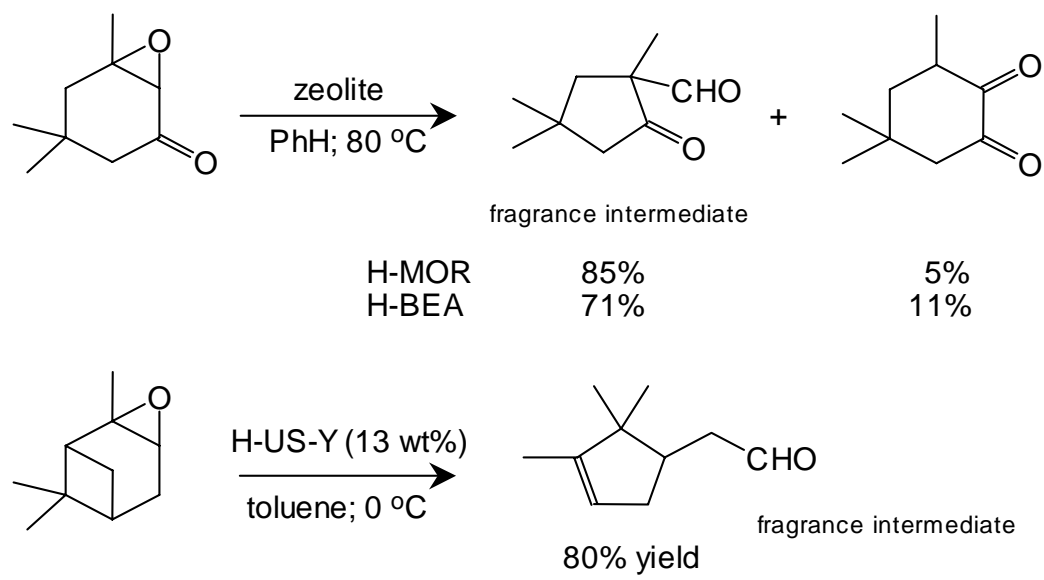

Fig. 3 Zeolite-catalyzed rearrangements of epoxides.

Acid-catalyzed rearrangement of epoxides to carbonyl compounds is another widely used reaction in fine chemicals manufacture. Lewis acids such as $\mathrm{ZnCl}_{2}$ are generally used, often in stoichiometric amounts, to perform such transformations. According to recent reports [14-16], zeolites can be used as recyclable solid acid catalysts for these reactions. Two commercially relevant examples are shown in Fig. 3. The rearrangement of $\alpha$-pinene oxide to campholenic aldehyde (see Fig. 3) is of considerable commercial importance as the product is the precursor of the sandalwood fragrance, santalol. Solid acid catalysts for this reaction include modified H-USY zeolite [15] and Ti-beta zeolite (Al-free) [16]. With the latter selectivities up to $89 \%$ in the liquid phase and $94 \%$ in the vapor phase were obtained, exceeding the best yields obtained with homogeneous Lewis acids.

Other reactions that have been reported to be catalyzed by zeolites include the Fries rearrangement [17], the Claisen rearrangement [18], and the Pechmann condensation of phenols with $\beta$-keto esters [19]. Hence, we expect that catalysis by zeolites or related solid acids will be widely applied in fine chemicals synthesis in the future.

Examples of the application of solid bases as catalysts are fewer than for solid acids. Nevertheless, a wide variety of materials are becoming available for use as solid-base catalysts [20]. In particular, layered double hydroxides (LDHs) such as hydrotalcite clays have been the focus of recent attention [21]. Synthetic hydrotalcites, of general formula $\left[\mathrm{Mg}_{8-\mathrm{x}} \mathrm{Al}(\mathrm{OH})_{16}\left(\mathrm{CO}_{3}\right)_{x / 2}\right] \mathrm{nH}_{2} \mathrm{O}$ are hydrated aluminum-magnesium hydroxides with a lamellar structure in which the excess positive charge is compensated by carbonate anions in the interlamellar space [20,21]. Calcination transforms hydrotalcites, via dehydroxylation and decarbonation, into strongly basic mixed magnesium-aluminium oxides that are useful solid-base catalysts for e.g., aldol [22], Knoevenagel [23, 24], and Claisen-Schmidt condensations [24] and epoxidation of electrophilic olefins with $\mathrm{H}_{2} \mathrm{O}_{2}$ [25].

Another approach to designing solid-base catalysts for use in organic synthesis is to attach organic bases to the surface of, for example, mesoporous silicas. For example, the aminopropyl-silica resulting from functionalization with 3-aminopropyl(trimethoxy)-silane was an active catalyst for Knoevenagel condensations [26]. Stronger solid-base catalysts are obtained by attaching guanidine bases to the surface. For example, the functionalization of mesoporous MCM-41 with 1,5,7-triazabicyclo$[4,4,0]$ dec-5-ene (TBD), using a surface glycidylation technique followed by reaction with TBD (Fig. 4), afforded an active catalyst for Knoevenagel condensations, Michael additions, and Robinson annulations [27]. In an alternative approach a bulky guanidine, N,N',N"-tricyclohexylguanidine was encapsulated in the super cages of hydrophobic zeolite $Y$ to give a ship-in-a-bottle guanidine that catalyzed the aldol reaction of acetone with benzaldehyde, affording 4-phenyl-4-hydroxybutan-2-one [28].

(C) 2000 IUPAC, Pure and Applied Chemistry 72, 1233-1246 


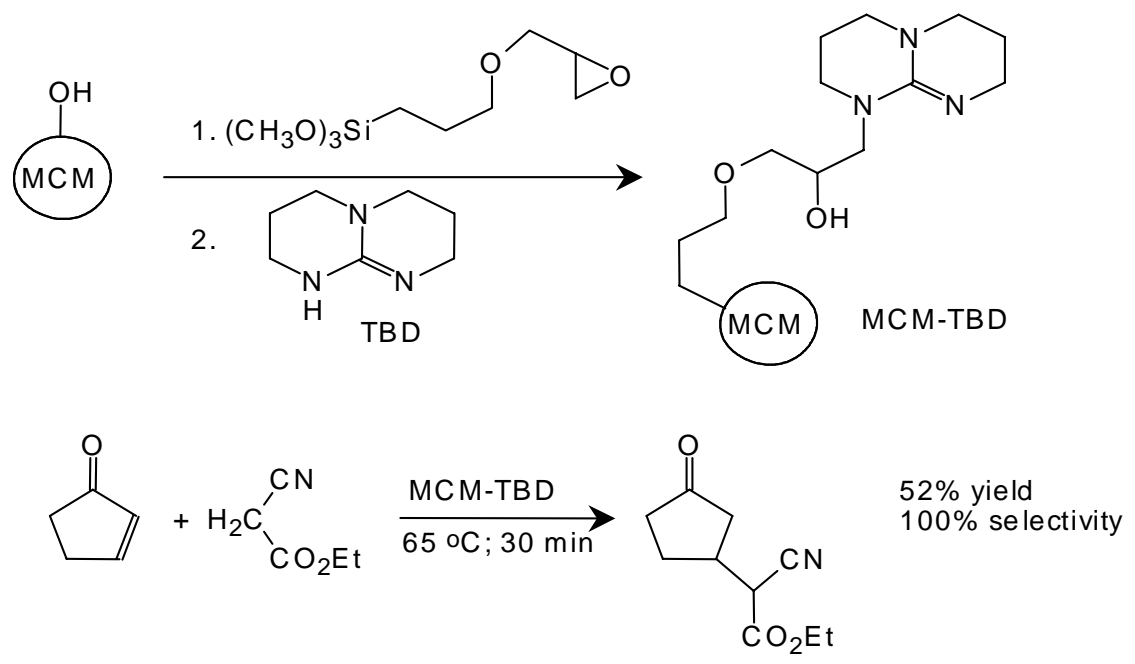

Fig. 4 Anchoring an organic base to MCM-41.

\section{CATALYTIC REDUCTION}

Catalytic hydrogenation is already widely used in industrial organic synthesis. A wide variety of functional groups can be efficiently hydrogenated, often with high degrees of chemo-, regio- and stereoselectivity. Nevertheless, new advances still continue to appear. For example, Rhône Poulenc [12] has succeeded in developing a catalyst for the direct hydrogenation of aromatic and aliphatic carboxylic acids, a notoriously difficult transformation. The reaction is performed in the vapor phase over a supported ruthenium/tin alloy catalyst at $250-300{ }^{\circ} \mathrm{C}$ and $1 \mathrm{bar}_{2}$ pressure. 1-Dodecanoic acid and trifluoroacetic acid afforded 1-dodecanal and fluoral, respectively, and an $\alpha, \beta$-unsaturated acid underwent chemoselective reduction to the corresponding $\alpha, \beta$-unsaturated aldehyde (Reaction 1) in $91 \%$ yield. Similarly, Mitsubishi has commercialized a process for the direct vapor-phase hydrogenation of aromatic, aliphatic, and unsaturated carboxylic acids, to the corresponding aldehydes, over zirconia or chromia catalysts [29].

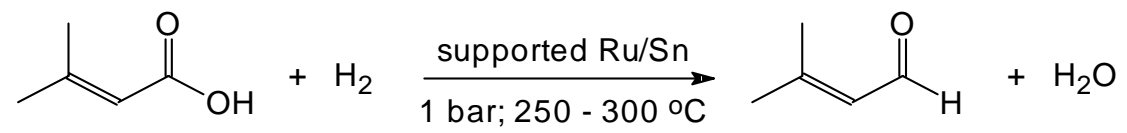

The Meerwein-Ponndorf-Verley (MPV) reduction is a widely used technology for the reduction of aldehydes and ketones to the corresponding alcohols. It involves the reaction of the substrate with a hydrogen donor, usually isopropanol, in the presence of an aluminium alkoxide (e.g., $\left.\mathrm{Al}\left(\mathrm{OPr}^{\mathrm{i}}\right)_{3}\right)$.In practice, MPV reductions often require stoichiometric amounts of the latter owing to the slow exchange of the alkoxy group in aluminium alkoxides. According to a recent report [30], zeolite beta is able to catalyse MPV reductions. The method is truly catalytic, and the catalyst can be readily separated, by simple filtration, and recycled. An additional benefit in the selective reduction of 4-tertbutylcyclohexanone was the selective formation of the thermodynamically less stable cis-alcohol, an important fragrance chemical intermediate, in $>95 \%$ yield. In contrast, classical MPV reduction affords predominantly the trans-isomer. Preference for the cis-isomer was attributed to transition state selectivity imposed by confinement of the substrate in the zeolite pores (Fig. 5).

(C) 2000 IUPAC, Pure and Applied Chemistry 72, 1233-1246 


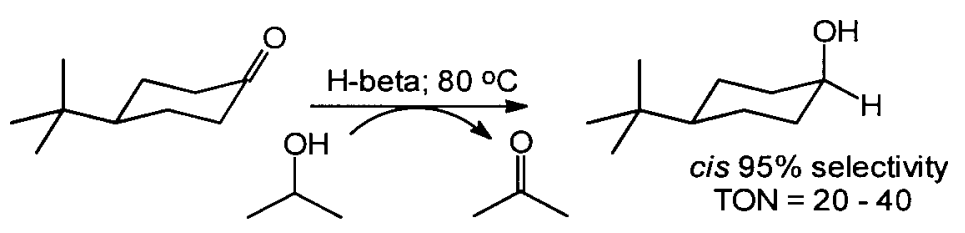

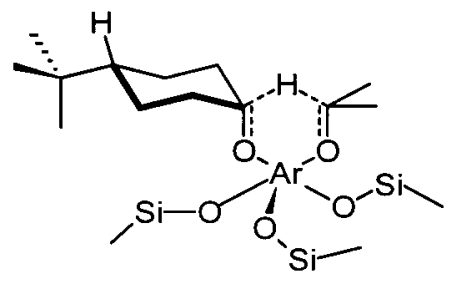

cis

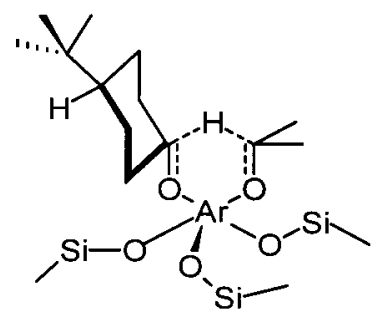

trans

Fig. 5 Zeolite beta-catalyzed stereoselective MPV reduction.

\section{CATALYTIC OXIDATION}

The selective oxidation of alcohols to the corresponding carbonyl compounds plays a central role in organic synthesis. In the fine chemicals industry there exists a pressing need for green methods for these conversions.

Methods should preferably use a clean oxidant (e.g., $\mathrm{O}_{2}$ or $\mathrm{H}_{2} \mathrm{O}_{2}$ ) and be effective with a broad range of alcohol substrates. We have recently developed a method for the aerobic oxidation of alcohols (Fig. 6) using a combination of $\mathrm{RuCl}_{2}\left(\mathrm{Ph}_{3} \mathrm{P}\right)_{3}$ and TEMPO (2,2',6,6'-tetramethylpiperidine- $N$-oxyl) as the catalyst [31]. The method is effective for the conversion of a broad range of primary, secondary, and allylic alcohols to the corresponding aldehydes or ketones. Many other examples of selective catalytic aerobic oxidation of alcohols have been recently reported [32].

In the fine chemicals industry, hydrogen peroxide is often the oxidant of choice, since it can be used in existing batch equipment. The titanium(IV)-silicalite (TS-1) catalyst developed by Enichem [33] is an extremely versatile catalyst for a variety of synthetically useful oxidations with $30 \%$ aqueous hydrogen peroxide, for example, epoxidation, alcohol oxidation, phenol hydroxylation to a mixture of catechol and hydroquinone, and ketone ammoximation with $\mathrm{NH}_{3} / \mathrm{H}_{2} \mathrm{O}_{2}$ [34]. The latter provides an atom-efficient, low-salt alternative to traditional oxime formation by reaction of the ketone with a hydroxylamine salt. It is of commercial interest for the synthesis of cyclohexanone oxime, the precursor of caprolactam, via Beckmann rearrangement of the oxime.

Ammoximation proceeds via in situ formation of hydroxylamine by titanium-catalyzed oxidation of ammonia with hydrogen peroxide in the micropores of the catalyst. Subsequent reaction of hydroxylamine with the ketone occurs in the bulk solution, which means that it is applicable, in principle, to any ketone (or aldehyde), for example, $p$-hydroxyacetophenone was converted to the corresponding oxime [35]. Beckmann rearrangement of the latter affords the analgesic, paracetamol (Fig. 7).

\section{CATALYTIC C-C BOND FORMATION}

An important catalytic methodology for generating $\mathrm{C}-\mathrm{C}$ bonds is carbonylation. It is used, for example, in the manufacture of acetic acid by methanol carbonylation [36]. Since carbonylations are generally 
<smiles>[R]C([R])O</smiles>

Substrate

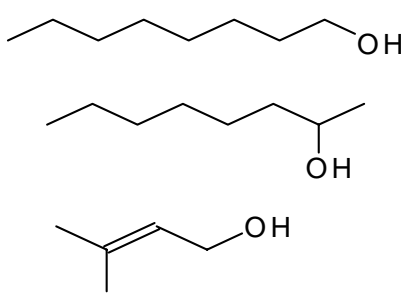

$\mathrm{PhCH}\left(\mathrm{CH}_{3}\right) \mathrm{OH}$

$\mathrm{PhCH}_{2} \mathrm{OH}$

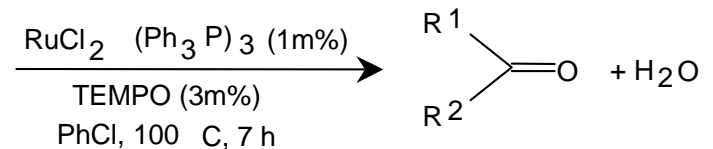

$\mathrm{PhCl}, 100 \mathrm{C}, 7 \mathrm{~h}$

Fig. 6 Ruthenium/TEMPO-catalyzed aerobic alcohol oxidations.<smiles>CC(=O)Nc1ccc(O)cc1</smiles>

Fig. 7 Paracetamol synthesis via ammoximation.

$100 \%$ atom-efficient processes, they are also finding applications in fine chemicals synthesis. An elegant example is the Hoechst-Celanese process (Fig. 8) for the manufacture of ibuprofen [37], an over-thecounter analgesic with an annual production in excess of 8,000 tons. In this process ibuprofen is produced in two catalytic steps (hydrogenation and carbonylation), in $100 \%$ atom efficiency, from $p$-isobutylacetophenone. The latter is produced by Friedel-Crafts acetylation of isobutylbenzene in liquid hydrogen fluoride. Although the latter is completely recycled there remains a need for a truly catalytic procedure, for example, using a solid acid or an ionic liquid (see later).

Another elegant example of a $100 \%$ atom-efficient carbonylation is the one-step conversion of an aldehyde, $\mathrm{CO}$ and an amide to an acylamino acid via palladium-catalyzed amidocarbonylation (Reaction 2) [38].

(C) 2000 IUPAC, Pure and Applied Chemistry 72, 1233-1246 

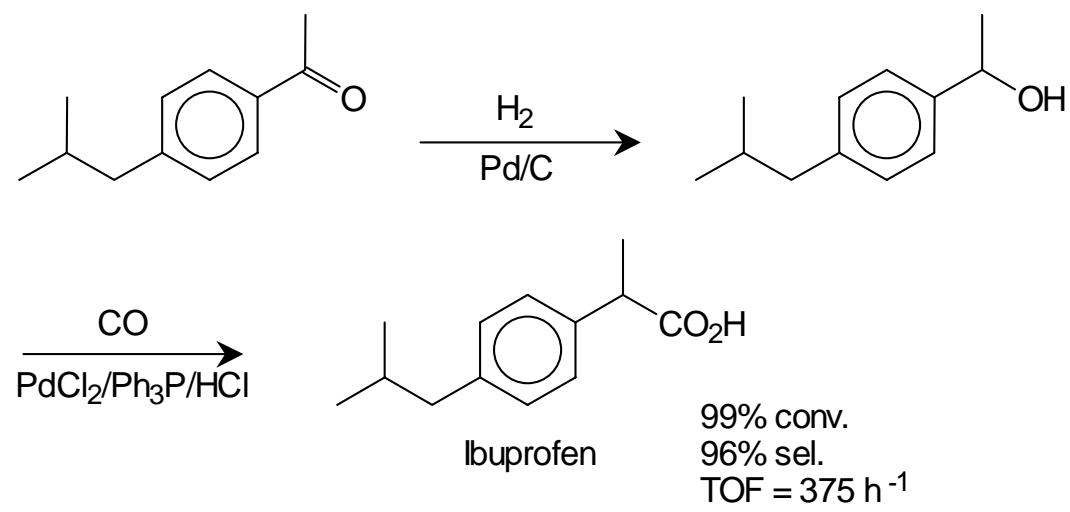

Fig. 8 Hoechst-Celanese process for ibuprofen.

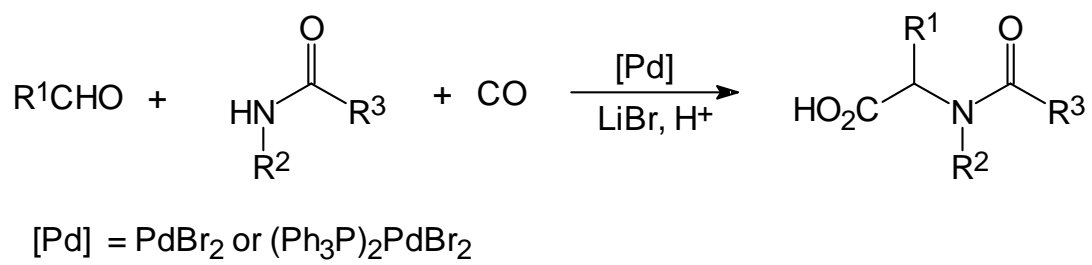

\section{CATALYSIS IN NOVEL MEDIA}

Another major problem in the fine chemicals industry is the use of solvents. Environmental legislation has severely curtailed the use of chlorinated hydrocarbons, for example. The best solvent is no solvent, and if a solvent (diluent) is needed, it should preferably be water, which is nontoxic, noninflammable, inexpensive, and abundantly available.

Because water is immiscible with most organic substrates this means that reactions are performed in liquid-liquid biphasic systems by employing phase-transfer catalysis [39]. Alternatively, one can employ water-soluble transition metal complexes to catalyze reactions in the aqueous phase. Success depends on the substrate dissolving to a small extent in the water phase. An advantage of such biphasic organometallic catalysis [40] is that the catalyst, which resides in the water phase, is readily recovered, by phase separation, and recycled. Hence, it provides an attractive alternative to conventional methods for heterogenization of homogeneous catalysts, which often leads to loss of activity and/or selectivity.

An elegant example of the industrial application of biphasic organometallic catalysis is the Ruhrchemie-Rhône Poulenc process for the hydroformylation of propylene to $n$-butanal (Reaction 3) which employs a water-soluble rhodium(I) complex of trisulfonated triphenylphosphine (tppts) as the catalyst [41].

$$
\curvearrowright+\mathrm{CO}+\mathrm{H}_{2} \underset{\mathrm{H}_{2} \mathrm{O}}{\stackrel{\mathrm{Rh} / \mathrm{tppts}}{\longrightarrow}} \overbrace{95 \% \text { selectivity }}^{\mathrm{CHO}}
$$




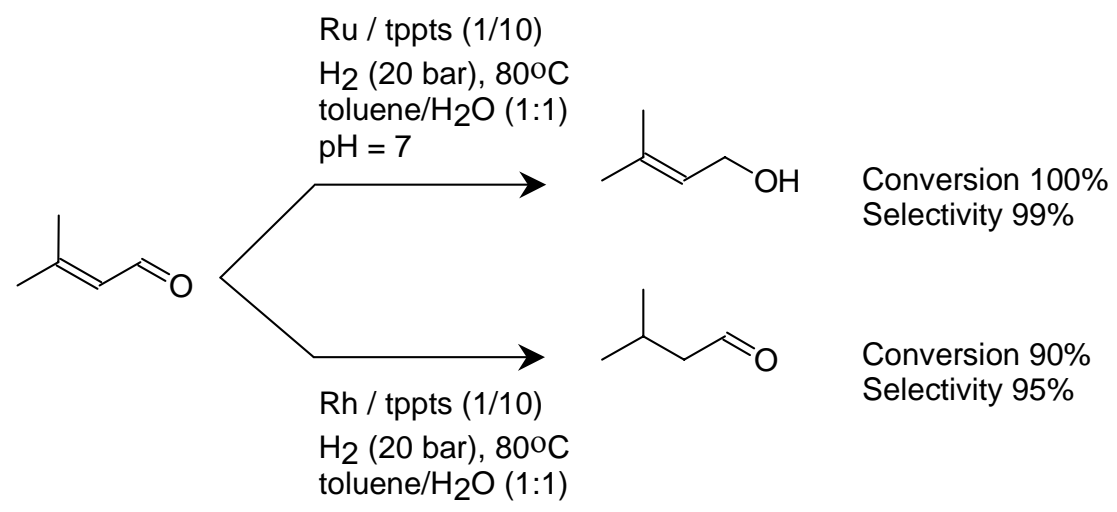

Fig. 9 Chemoselective hydrogenation of an unsaturated aldehyde.

This concept is applicable to a wide variety of transition metal-catalyzed processes [42], for example, the chemoselective hydrogenation of unsaturated aldehydes (Fig. 9) [43].

We found that the water-soluble palladium(0) complex, Pd(tppts) ${ }_{3}$ catalyzes the selective carbonylation of benzylic alcohols in an acidic aqueous medium [44]. We applied this methodology to the synthesis of ibuprofen via biphasic carbonylation of 1-(4-isobutylphenyl)ethanol (Reaction 4) [45]. The same catalyst was also used for the biphasic carbonylation of benzyl halides [46], and the hydrocarboxylation of olefins [47].

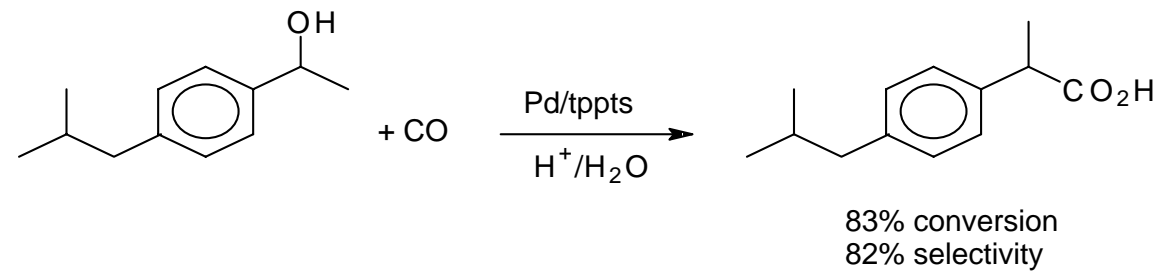

Other nonconventional reaction media have also attracted attention recently. For example, in the fluorous biphasic concept, developed by Horvath and Rabai [48], the catalyst is contained in a perfluorocarbon phase, by employing perfluorinated ligands, while the substrate and product reside in a second organic phase. This elegant concept has been applied to, for example, rhodium-catalyzed hydroformylation [48].

The use of supercritical carbon dioxide as a solvent for catalytic conversions, (e.g., hydrogenation) is also gaining in importance [49]. Interestingly, the use of perfluorinated ligands, developed for fluorous biphasic systems, also promotes the solubility of metal complexes in supercritical carbon dioxide [50].

Another exciting development in the context of clean chemistry is the use of ambient temperature ionic liquids, such as 1-methyl-3-ethylimidazolium, [emim ${ }^{+}$salts, as novel reaction media for a wide variety of processes [51,52]. For example, the ionic liquid derived from [emim] $\mathrm{Cl}$ and $\mathrm{AlCl}_{3}$ proved to be an excellent medium (and catalyst) for Friedel-Crafts acylations [53]. Ionic liquids have several advantages as reaction media. They have effectively no vapor pressure and, hence, no emissions to the atmosphere, they are thermally stable and are liquid over a wide temperature range (typically $300{ }^{\circ} \mathrm{C}$ )

(C) 2000 IUPAC, Pure and Applied Chemistry 72, 1233-1246 


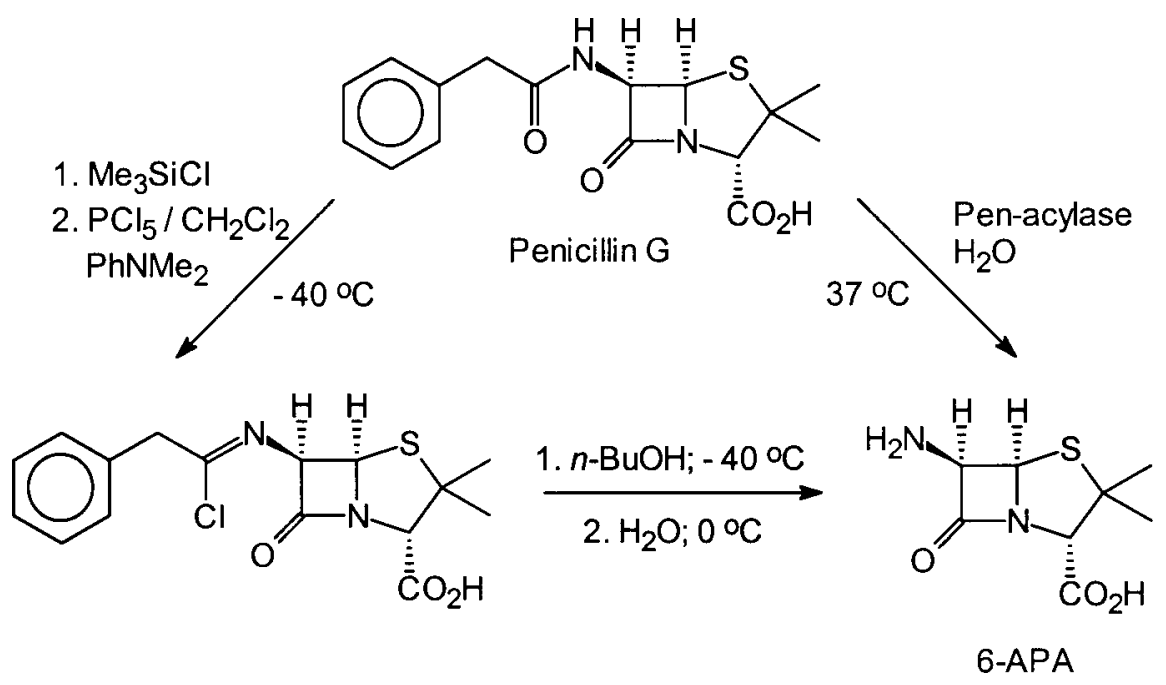

Fig. 10 Chemical vs enzymatic route to 6-APA.

and they are outstanding solvents for a wide range of organic, inorganic, and polymeric materials. Expectations are high, and it has been suggested that ambient-temperature ionic liquids will form the basis of a new industrial technology that will revolutionize the methodology of synthetic organic chemistry [51].

\section{BIOCATALYSIS}

Biocatalytic conversions have many advantages in the context of green chemistry. They are generally performed in water at ambient temperature and pressure and often involve fewer steps than conventional chemical procedures because protection and deprotection of functional groups is often not required. For example, enzymatic hydrolysis of penicillin G to 6-APA (Fig. 10) proceeds in one step in water at $37^{\circ} \mathrm{C}$ while chemical deacylation requires three steps, a temperature of $-40^{\circ} \mathrm{C}$, and various stoichiometric reagents, resulting in a high $\mathrm{E}$ factor. However, the primary motivation for switching from chemical to enzymatic deacylation was to avoid the use of dichloromethane as solvent [54].

Another advantage of biocatalysis is that chemo-, regio- and stereoselectivities are attainable which are difficult or impossible to achieve by chemical means. Relevant examples are the microbial ring hydroxylation (Reaction 5) and side-chain oxidation (Reaction 6) of heteroaromatics developed by Lonza [55]. Such conversions would not be possible by conventional chemical means.

\section{ASYMMETRIC CATALYSIS}

Another major trend is toward the development of products that are more targeted in their action and have fewer undesirable side effects. In the case of biologically active molecules (e.g., pharmaceuticals and pesticides), this had led to the marketing of chiral molecules as the pure enantiomer that is responsible for the desired bioactivity. This, in turn, has created an increasing demand for efficient methodologies for the synthesis of enantiomerically pure compounds.

The same reasoning applies to the synthesis of pure enantiomers as to organic syntheses in general: the methods should be atom efficient (i.e., involve catalysis rather than stoichiometric reagents). Consequently, attention has been increasingly focused on asymmetric catalysis, using either enzymes or chiral metal complexes [56]. 
<smiles>O=C(O)c1cccnc1</smiles><smiles></smiles><smiles>CCc1ccc(C)nc1</smiles><smiles>Cc1ccc(CC(=O)O)cn1</smiles>

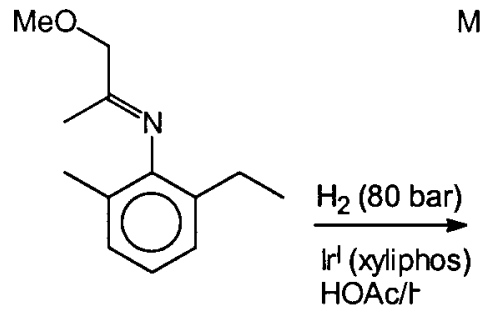
$50^{\circ} \mathrm{C} / 4 \mathrm{~h}$<smiles>CCc1cccc(C)c1NC(C)COC</smiles>

(S)<smiles>CCc1cccc(C)c1N(C(=O)CCl)C(C)COC</smiles>

(S)-Metolachlor

$80 \%$ ee

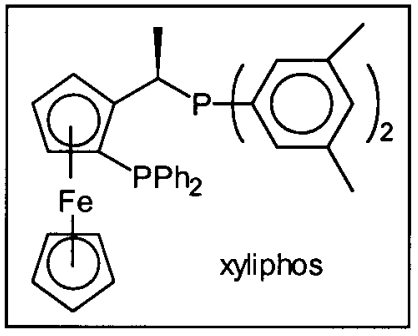

$S / C=750.000$

Fig. 11 Production of (S)-metolachlor by enantioselective hydrogenation of an imine.

Because chiral metal complexes tend to be very expensive catalysts it is important, for industrial application, that they are very efficient (i.e., have a high turnover frequency). An impressive example of the sort of efficiency that can be achieved in asymmetric hydrogenation is provided by the Novartis process for the synthesis of the optically active herbicide, (S)-metolachlor [57]. The key step (Fig. 11) involves the asymmetric hydrogenation of a prochiral imine catalyzed by an iridium(I) complex of a chiral ferrocenyldiphosphine. The substrate/catalyst ratio in this step is 750000 , and 1 million turnovers were achieved in $6 \mathrm{~h}$. The product has an ee of $80 \%$. Higher ees can be obtained at lower substrate/ catalyst ratios but are not actually necessary for this product.

(C) 2000 IUPAC, Pure and Applied Chemistry 72, 1233-1246 


\section{CONCLUSION}

The widespread application of atom-efficient, catalytic methodologies in the manufacture of fine chemicals is the key to waste reduction. Clearly, there are many exciting developments with regard to novel catalytic materials and novel reaction media, many of which will find commercial applications in the near future. It is also apparent that traditional interdisciplinary barriers are disappearing and that the key to success is a multidisciplinary approach that integrates catalysis (homogeneous, heterogeneous, and enzymatic) with organic chemistry and process engineering.

\section{REFERENCES}

1. R. A. Sheldon. CHEMTECH March 1994, pp. 38-47.

2. R. A. Sheldon. Chem. Ind. (London) 903 (1992) and 12 (1997).

3. R. A. Sheldon. J. Chem. Tech. Biotechnol. 68, 381 (1997).

4. R. A. Sheldon. J. Mol. Catal. A: Chemical 107, 75 (1996).

5. P. T. Anastas and J. C. Warner. Green Chemistry: Theory and Practice, Oxford Univ. Press, Oxford (1998).

6. P. T. Anastas and T. C. Williamson (Eds.). Green Chemistry: Frontiers in Chemical Synthesis and Processes, Oxford Univ. Press, Oxford (1998).

7. P. T. Anastas and C. A. Farris (Eds.). Benign by Design: Alternative Synthetic Design for Pollution Prevention, ACS Symp. Ser. nr. 577, ACS, Washington DC (1994).

8. R. A. Sheldon. In Industrial Environmental Chemistry, D. T. Sawyer and A. E. Martell (Eds.), pp. 99-119, Plenum, New York (1992); R. A. Sheldon. In Precision Process Technology, M. P. C. Weijnen and A. A. H. Drinkenburg (Eds.), pp. 125-138, Kluwer, Dordrecht (1993).

9. B. M. Trost. Science 254, 1471 (1991); B. M. Trost. Angew. Chem. Int. Ed. Engl. 34, 259 (1995).

10. P. N. Davey, C. D. Richardson, C. P. Newman, B. R. Hart. Eur. Pat. Appl. 0784043 (1997) to Quest International.

11. R. S. Downing, H. van Bekkum, R. A. Sheldon. Cattech 2, 95 (1997).

12. S. Ratton. Chem. Today, March/April 1997, pp. 33-37.

13. A. P. Singh and A. K. Pandey. J. Mol. Catal. A: Chemical 123, 141 (1997).

14. J. A. Elings, H. E. B. Lempers, R. A. Sheldon. Stud. Surf. Sci. Catal. 105, 1165 (1997).

15. W. F. Hölderich, J. Röseler, G. Heitmann, A. T. Liebens. Catal. Today 37, 353 (1997).

16. P. J. Kunkeler, J. C. van der Waal, J. Bremmer, B. J. Zuurdeeg, R. S. Downing, H. van Bekkum. Catal. Lett. 53, 135 (1998).

17. For example see: A. J. Hoefnagel and H. van Bekkum. Appl. Catal. A: General 97, 87 (1993).

18. J. A. Elings, R. S. Downing, R. A. Sheldon. Stud. Surf. Sci. Catal. 94, 487 (1995).

19. E. A. Gunnewegh, A. J. Hoefnagel, R. S. Downing, H. van Bekkum. Recl. Trav. Chim. Pays-Bas 115, 226 (1996).

20. H. Hattori. Chem. Rev. 95, 537 (1995).

21. S. Carlino. Chem. Brit. Sept. 1997, pp. 59-62; F. Cavani, F. Trifiro, A. Vaccari. Catal. Today 11, 173 (1991); A. Vaccari. Catal. Today 41, 53 (1998); A. Vaccari. Appl. Clay Sci. 14, 161 (1999).

22. F. Figueras, D. Tichit, M. Bennari Naciri, R. Ruiz. In Catalysis of Organic Reactions, F. E. Herkes (Ed.), pp. 37-49, Marcel Dekker, New York (1998).

23. A. Corma, R. M. Martin-Aranda. Appl. Catal. A: General 105, 271 (1993).

24. M. J. Climent, A. Corma, S. Iborra, J. Primo. J. Catal. 151, 66 (1995).

25. C. Cativiela, F. Figueras, J. M. Fraile, J. I. Garcia, J. M. Mayoral. Tetrahedron Lett. 36, 4125 (1995); see also K. Kaneda, S. Ueno, d K. Ebitani. Curr. Top. Catal. 1, 91 (1997). 
26. D. Brunel. Micropor. Mesopor. Mat. 27, 329 (1999); D. J. Macquarrie. Green Chemistry 1, 195 (1999).

27. Y. V. Subba Rao, D. E. De Vos, P. A. Jacobs. Angew. Chem. Int. Ed. Engl. 36, 2661 (1997).

28. R. Sercheli, A. L. B. Ferreira, M. C. Guerreiro, R. M. Vargas, R. A. Sheldon, U. Schuchardt. Tetrahedron Lett. 38, 1325 (1997).

29. T. Yokoyama, T. Setoyama, N. Fujita, M. Nakajima, T. Maki. Appl. Catal. A: General 88, 149 (1992).

30. E. J. Creyghton, S. D. Ganeshie, R. S. Downing, H. van Bekkum. J. Mol. Catal. A: Chemical 115, 457 (1997).

31. A. Dijksman, I. W. C. E. Arends, R. A. Sheldon. Chem. Commun.1591 (1999).

32. For example see: I. E. Marko, P. R. Giles, M.Tsukazaki, I. Chellé-Regnaut, C. J. Urch, S. M. Brown. J. Am. Chem. Soc. 119, 12661 (1997); B. Hinzen, R. Lenz, S. V. Ley. Synthesis 977 (1998); A. Bleloch, B. F. G. Johnson, S. V. Ley, A. J. Price, D. S. Shephard, A. W. Thomas. Chem. Commun. 1907 (1999); K. Kaneda, T. Yamashita, T. Matsushita, K. Ebitani. J. Org. Chem. 63, 1750 (1998); T. Matsushita, K. Ebitani, K. Kaneda. Chem. Commun. 265 (1999); F. Vocanson, Y. P. Guo, J. L. Namy, H. B. Kagan. Synth. Commun. 28, 2577 (1998); A. Hanyu, E. Takewawa, S. Sakaguchi, Y. Ishii. Tetrahedron Lett. 39, 5557 (1998); I. E. Marko, P. R. Giles, M. Tsukazaki, S. M. Brown, C. J. Urch. Science 274, 2044 (1996).

33. B. Notari. Stud. Surf. Sci. Catal. 37, 413 (1988).

34. V. Romano, A. Esposito, F. Maspero, C. Neri, M. G. Clerici. Chim. Ind. (Milan) 72, 610 (1990).

35. J. le Bars, J. Dakka, R. A. Sheldon. Appl. Catal. A: General 136, 69 (1996).

36. P. M. Maitlis, A. Haynes, G. J. Sunley, M. J. Howard. J. Chem. Soc. Dalton Trans. 2187 (1996).

37. V. Elango, M. A. Murphy, B. L. Smith, K. G. Davenport, G. N. Mott, G. L. Moss. US Patent 4981995 (1991) to Hoechst Celanese Corp.

38. M. Beller, M. Eckert, F. Vollmüller, S. Bogdanovic, H. Geissler. Angew. Chem. Int. Ed. Engl. 36, 1494 (1997); M. Beller, M. Eckert, W. A. Moradi, H. Neumann. Angew. Chem. Int. Ed. Engl. 38, 1454 (1999).

39. Y. Sasson and R. Neumann (Eds.). Handbook of Phase Transfer Catalysis, Blackie Academic, Glasgow (1997); C. M. Starks, C. L. Liotta, M. Halpern. Phase Transfer Catalysis, Fundamentals, Application and Industrial Perspectives, Chapman and Hall, London (1994).

40. B. Cornils and W. A. Herrmann (Eds.). Aqueous Phase Organometallic Catalysis. Concepts and Applications, Wiley-VCH, Weinheim (1998).

41. B. Cornils and E. Wiebus. Recl. Trav. Chim. Pays-Bas 115, 211 (1996).

42. G. Papadogianakis and R. A. Sheldon. Specialist Periodical Reports, Catalysis, Vol. 13, J. J. Spivey (Ed.), pp. 114-193, The Royal Society of Chemistry (1997).

43. J. M. Grosselin, C. Mercier, G. Allmang, F. Grass. Organometallics 10, 2126 (1991); J. M. Grosselin and C. Mercier. J. Mol. Catal. A 63, L25 (1990).

44. G. Papadogianakis, L. Maat, R. A. Sheldon. J. Mol. Catal. A: Chemical 116, 179 (1997).

45. G. Papadogianakis, L. Maat, R. A. Sheldon. J. Chem. Technol. Biotechnol. 70, 83 (1997).

46. C. W. Kohlpaintner and M. Beller. J. Mol. Catal. A: Chemical 116, 259 (1997).

47. G. Papadogianakis, G. Verspui, L. Maat, R. A. Sheldon. Catal. Lett. 47, 43 (1997); see also S. Tilloy, E. Monflier, F. Bertoux, Y. Castagnet, A. Mortreux. New J. Chem. 21, 529 (1997).

48. I. T. Horvath and J. Rabai. Science 266, 72 (1994); I. T. Horvath. Acc. Chem. Res. 31, 641 (1998).

49. M. G. Hitzler, F. R. Smail, S. K. Ross, M. Poliakoff. Org. Proc. Res. Dev. 2, 137 (1998).

50. S. Kainz, D. Koch, W. Baumann, W. Leitner. Angew. Chem. Int. Ed. Engl. 109, 1699 (1997).

51. K. R. Seddon. J. Chem. Technol. Biotechnol. 68, 347 (1997); K. R. Seddon. Molten Salts Forum 5-6, 53 (1998).

(C) 2000 IUPAC, Pure and Applied Chemistry 72, 1233-1246 
52. Y. Chauvin, H. O. Olivier-Boubigou. CHEMTECH, Sept. 1995, pp. 26-30.

53. C. J. Adams, M. J. Earle, G. Roberts, K. R. Seddon. Chem. Commun. 2097 (1998).

54. A. Bruggink, E. C. Roos, E. de Vroom. Org. Proc. Res. Dev. 2, 128 (1998).

55. A. Kiener. CHEMTECH Sept. 1995, pp. 31-35.

56. R. A. Sheldon. Chirotechnology: the Industrial Synthesis of Optically Active Compounds, Marcel Dekker, New York (1993).

57. H.-U. Blaser and F. Spindler. Topics in Catalysis 5, 275 (1998). 